\title{
An apparatus for the study of classical fear conditioning
}

\author{
MELVIN L. GOLDSTEIN \\ Indiana University at Kokomo, Kokomo, Indiana 46901
}

A photograph of an apparatus for the study of classical fear conditioning in rats is presented.

The acquired drive, or classical fear conditioning, apparatus has been described in a previous paper (Goldstein, 1960), but a photograph of it has not previously been published. The apparatus consists of a two-compartment shock box, one compartment having a grid floor and the other a wooden floor. The two compartments are separated by a guillotine-type door. A photograph of the apparatus is shown in Figure 1.

The shock source used to activate the grids consists of a step-up transformer and a 250,000 -ohm fixed resistor which is wired in series with the rat. Voltages ranging from 0 to $1,000 \mathrm{~V}$, at relatively low amperages, may be obtained with this shock source.

The apparatus has been used to study the effect of UCS (shock) intensity on classical fear conditioning, backward conditioning (Goldstein, 1960), classical conditioning to background stimuli (Goldstein, 1974), the rat's sensitivity to electric shock (Goldstein, 1968), and the effect of limbic system lesions on acquisition and retention of a classically conditioned fear response (Goldstein, 1965; 1974; 1975). It has also been used to study stimulus compounding and the persistence of UCS intensity effects.

The apparatus has been found most useful, primarily, in parametric studies of the effect of UCS intensity variations on conditioning and in the study of the effects of limbic system lesions on conditioning.

\section{REFERENCES}

Goldstein, M. L. Acquired drive strength as a joint function of shock intensity and number of acquisition trials. Joumal of Experimental Psychology, 1960, 60, 349-358.

Goldstein, M. L. Effects of hippocampal, amygdala, hypothalamic, and parietal lesions on a classically conditioned fear response. Psychological Reports, 1965, 16, 211-219

Goldstein, M. L. Effects of lesions of the amygdaloid complex on peripheral shock thresholds and activity in the hooded rat. Journal of General Psy chology, 1968, 79, 59-74.

Preparation of this report was supported in part by a supply grant awarded by the Indiana University Office of Research and Advanced Studies (Grant No. 26-631-32).

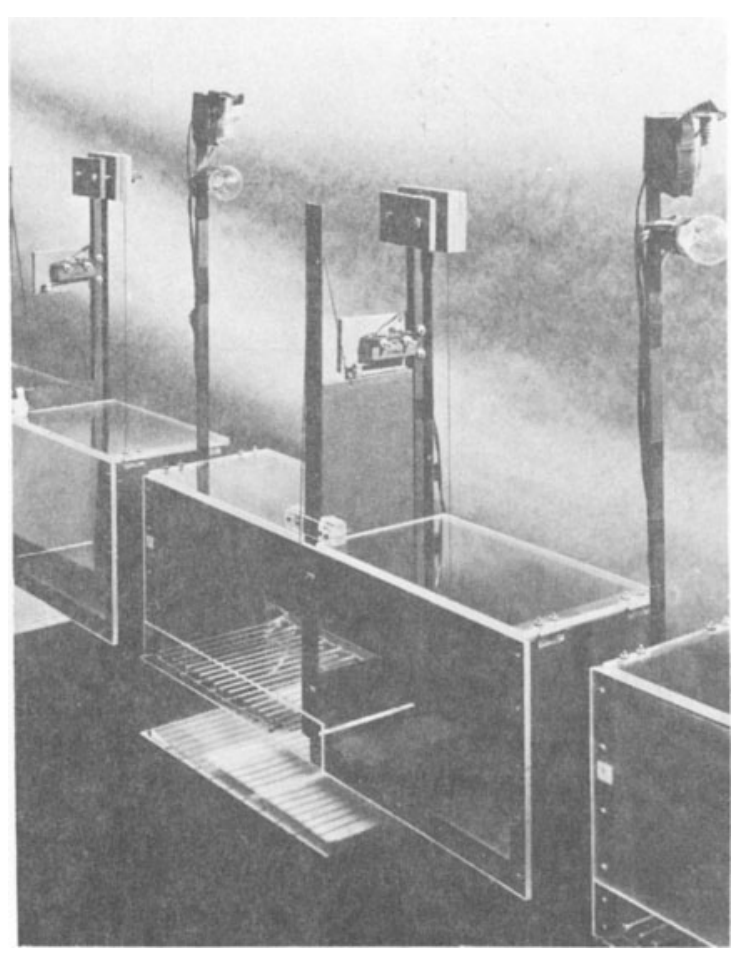

Figure 1. The acquired drive conditioning apparatus.

Goldstein, M. L. Effect of static background cues on classical fear conditioning. Journal of General Psy chology, 1974, 91, 145-151.

Goldstein, M. L. The effect of amygdalectomy on acquisition of a classically conditioned fear response. Bulletin of the Psy chonomic Society, 1974, 4, 465-466. (a)

Goldstein, M. L. The effect of amygdalectomy on long-term retention of an undertrained classically conditioned fear response. Bulletin of the Psychonomic Society, 1974, 4, 548-550. (b)

Goldstein, M. L. The effect of septal lesions on acquisition of a classically conditioned fear response. Bulletin of the Psy chonomic Society, 1975, 5, 182-184.

(Received for publication April 24, 1975.) 